\title{
DIFFERENTIATION OF THE CARABID ANTENNA CLEANER ${ }^{1}$
}

\author{
By T. F. Hlavac ${ }^{2}$ \\ Museum of Comparative Zoology \\ Harvard University
}

The antennae of most carabids are groomed by tightly packed setae on the protibia. The mouthparts are not employed in antenna cleaning in ground beetles, but are so used in many Coleoptera (Jander, 1966, table 2). A protibial antenna cleaner may be primitively absent only in Nototylus (Banninger 1927: 77I) but is secondarily lost in advanced paussines (Darlington $1950: 65$ ). There is great variation in the degree of development of the cleaning setae and in protibial structure. This paper describes and analyzes structural differentiation of the carabid antenna cleaner, and presents preliminary data on grooming behavior. Work on the fine structure and histology of the cleaning setae and associated glands is in progress and will be reported elsewhere.

The protibiae of about 100 genera representing 60 tribes were studied; 50 species were measured. A description of methods employed and a formal list of carabids examined in this study will be presented in a paper on prothoracic morphology of the Coleoptera.

Structure. The antenna grooming setae are located on the medial face of the tibia; there are two types of setal aggregations. The major cleaning element is the setal band (Figs. I, 2 I SB). It is composed of very tightly packed setae arranged in a single file that always begins near the anterior spur and may extend nearly horizontally across the width of the medial face (Figs. 2, 7, 9) or may extend vertically up the length of the tibia for a considerable distance (Figs. I, 3, I5 SB). The second type of cleaning cluster consists of relatively short, less densely packed vertical rows of setae, usually in single file, originating above the tibial spurs (Figs. I, 2 I ASR, PSR). In a few carabids dense setal rows, which are probably used in grooming, extend above both the anterior and posterior

\footnotetext{
${ }^{1}$ A preliminary version of this work was submitted as a portion of a thesis to the Biology Department, Harvard University, in partial fulfillment of the requirements for the Ph.D. degree.

${ }^{2} I$ thank Drs. P. J. Darlington, Jr. and J. F. Lawrence for reading the manuscript. This work was supported, in part, by NSF GB12346, P. J. Darlington, Jr., Principal Investigator; and NSF GB 19922, Reed Rollins, Principal Investigator.

Manuscript received by the editor May 14, 1971.
} 

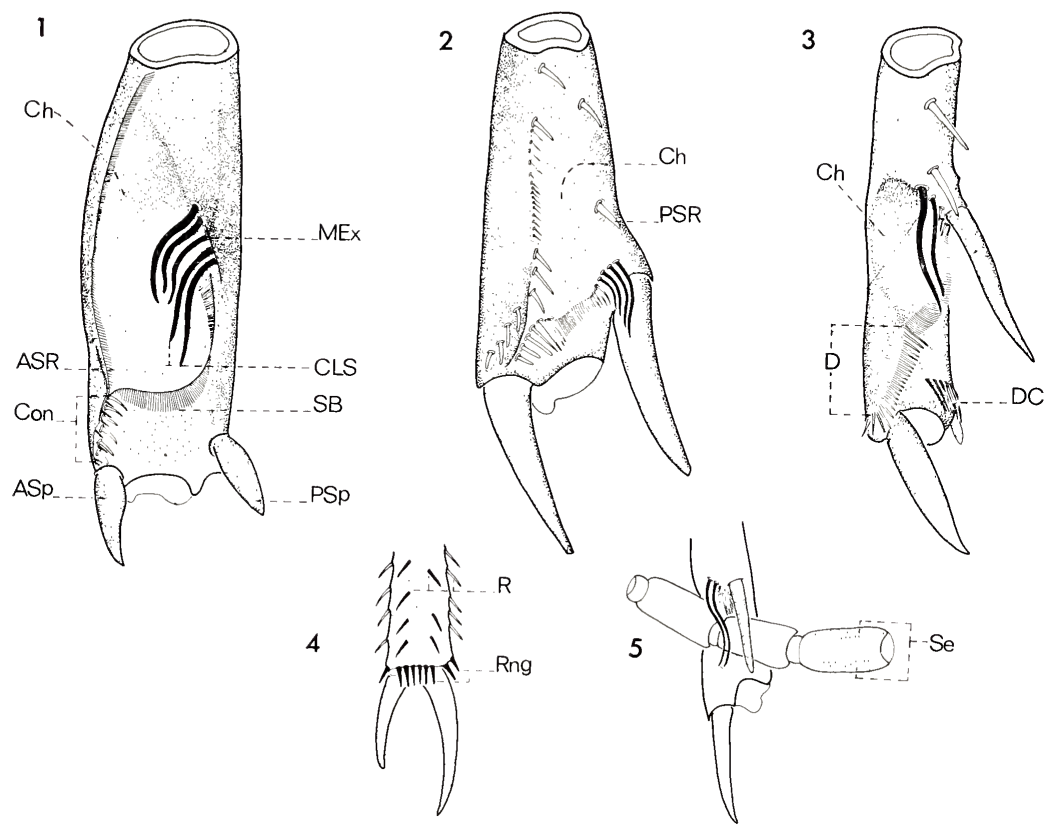

Figs. 1-3. Medial views of distal region of protibia.

Fig. 1. Metrius contractus; Fig. 2. Carabus nemoralis.

Fig. 3. Pterostichus lucublandus.

Fig. 4. Carabus nemoralis mesotibia. medial view.

Fig. 5. Pterostichus lucublandus, medial view of protibia with a section of the antenna in place for grooming.

spurs (Fig. 7); in others only the anterior row is so developed (Figs. 9, II, I3, 21, 23, 25). In many advanced forms both rows are either absent or consist of widely spaced setae that may not be employed in grooming (Figs. I7, I9, 3I).

One or a few long, thick, sinuous bristles at the proximal end of the band serve to guide the antenna to, and clamp it against, the setal band during grooming, (Figs. I, $22 \mathrm{CLS}$ ). In a few genera (Omophron, Elaphrus) these enlarged setae are straight. Clamp setae are probably modified band setae.

Each group of protibial antenna cleaning setae can be homologized with clusters of bristles on a non-compressed meso- or metatibia. Tibial setae in the Carabidae can be divided into a number $(4-6)$ of vertical rows extending nearly the full length of the tibia and into a horizontal ring of setae that run about the circumference of 
the tibial apex, (Fig. 4 R. Rng). The ring and row setae are subject to much variation in size, number and density. In addition, other setae may be present that are not organized into distinct clusters but are distributed randomly over the tibial surface.

When the insertions of the spurs of the middle or hind tibia are more than slightly separated, a setal row extends above each, e.g., Carabus (Fig. 4). In such forms, a number of ring setae are found between the spurs. The medial aspect of the tibia consists then of some horizontal ring setae between the vertical setal rows and the spurs. The geometry of these setal aggregations relative to each other and to the spurs on the mesotibia is similar to that of the protiba of some carabids, e.g., Carabus, Opisthius (Figs. 7 and 9). As a preliminary hypothesis, the setal band of the protibia is considered to be serially homologous to that portion of the setal ring between the spurs in the other legs, and the anterior and posterior rows are serially homologous to the setal rows above the spurs. This hypothesis assumes, of course, the existence of a similar setal organization on all tibiae in primitive forms before some of the protibial setae became densely packed and specialized for antenna cleaning. The evolution of the carabid protibia can be looked at as divergence from the unspecialized configuration of the mesotibia. One important component of this divergence is the modification of protibial structure for antenna grooming. The amount of proximal lengthening of the setal band is the best single indicator of protibial specialization for antenna cleaning.

The length of the setal band (measured along the tibial long axis from the anterior spur insertion to the most proximal clamp seta) over the total length of the tibia (up to the articular head) or $\mathrm{SB} / \mathrm{Tb}$ $X I 00$ is a simple measure of setal band development. This method underestimates the length of a sinuous or horizontal band, particularly those of grades A and C. In the least specialized forms, (cicindelines, Opisthius), the setal band is almost completely horizontal, located near the distal margin of the medial face, and $\mathrm{SB} / \mathrm{Tb}$ is less than 10\%. In carabines (except Pamborus, Jeannel I94I, Fig. 98), cychrines and in the nebriines the band first extends vertically for a very short distance, where it is confluent with the anterior row, and then swings horizontally across the medial face; $\mathrm{SB} / \mathrm{Tb}$ is between $I O$ and 20 per cent. In these forms, while the band is shifted proximally for only a short distance, the posterior spur is shifted as well to maintain the geometric relationship between spurs and band. Much greater proximal shifts of the band are associated with a shift in spur position in many carabids. For example, $\mathrm{SB} / \mathrm{Tb}$ 

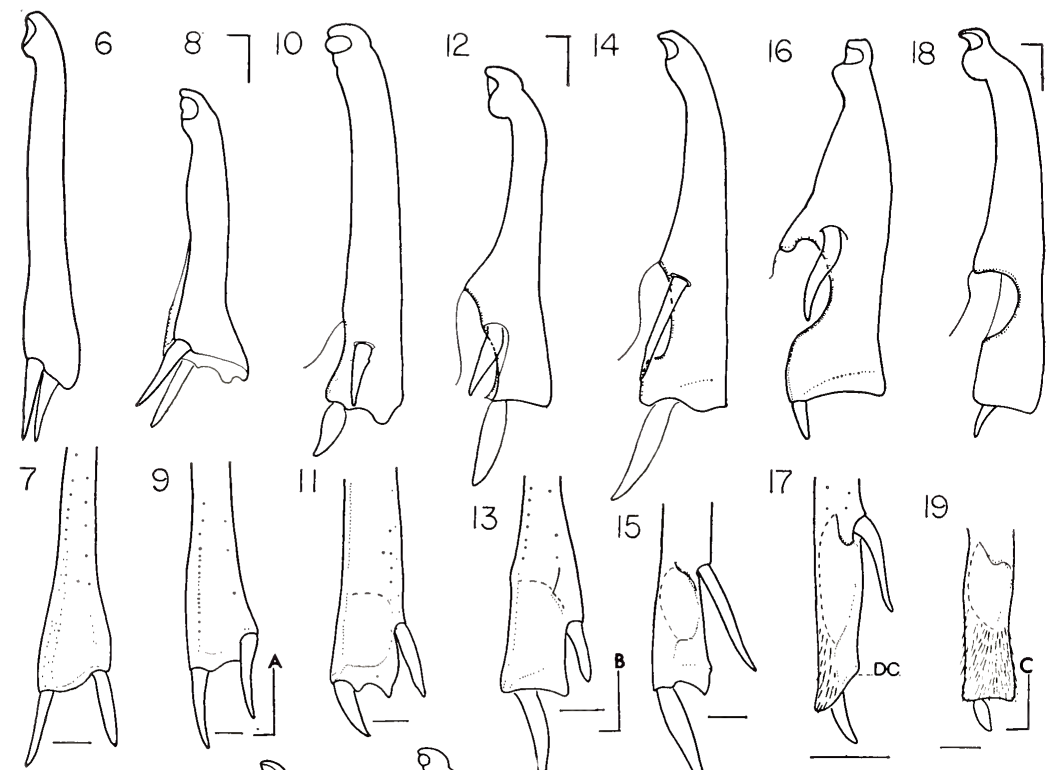

$17: 19$
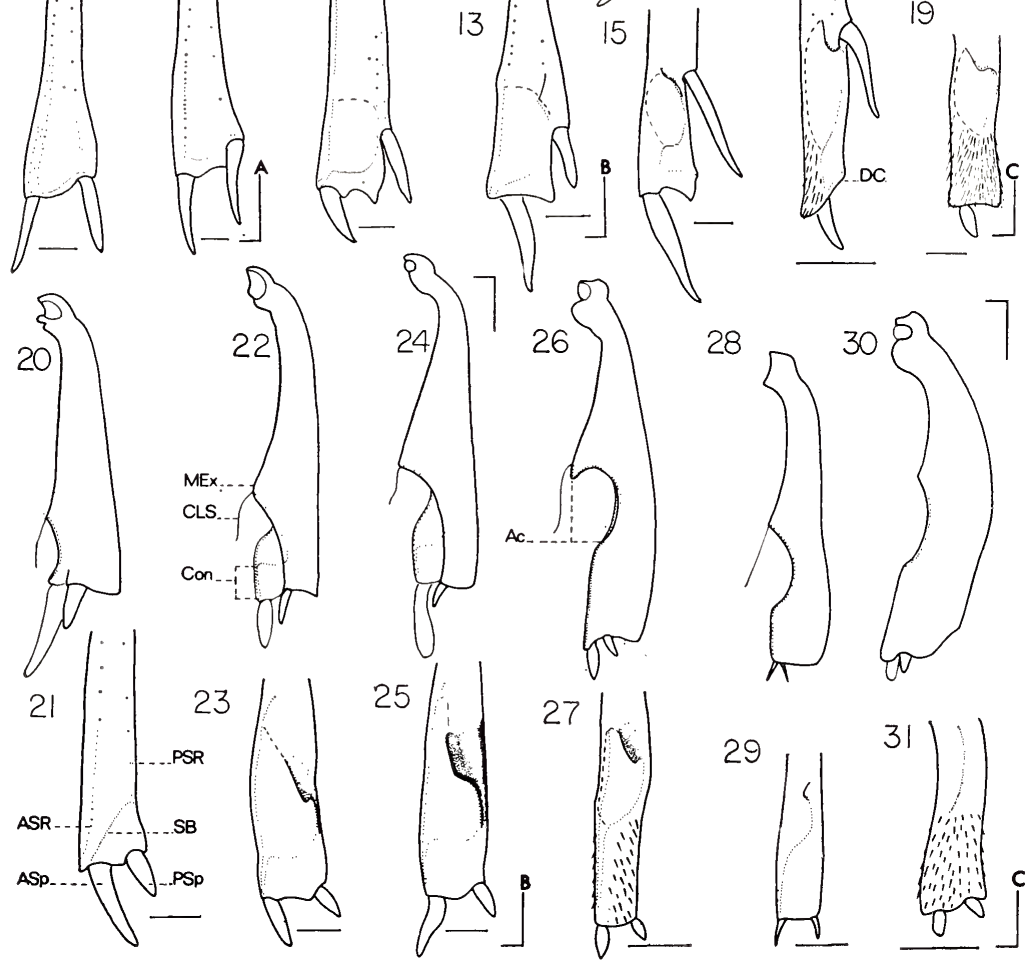
is 33 per cent in Hiletus (Figs. IO, I I), 37 per cent in Nomius Figs. I2, I3), 46 per cent in Pterostichus (Figs. I 4, I5) and 52 per cent in Helluomorphroides (Figs. I6, I7). In each case the posterior spur is located close to or at the level of the most proximal clip seta.

In a few carabid taxa, a large proximal development of the setal band has occurred without any movement of the posterior spur. For example, $\mathrm{SB} / \mathrm{Tb}$ is 30 per cent in Trachypachus (Figs. 20, $2 \mathrm{I}$ ), 40 per cent in Metrius (Figs. 24, 25), 55 per cent in Tropopsis (Figs. 26, 27), and 58 per cent in Gehringia (Figs. 28, 29). Bell ( I964) stated that only one tibial spur is found in Gehringia. In fact, two small apical spurs are present (Figs. 28, 29) as well as a "spinose hair" which Bell thought earlier authors had mistaken for the posterior spur.

The setal band in a few forms differs little in position from that of ring setae on the mesotibia (compare Figs. 3, 4, 6, 9). Additional modification of the setal band occurs with (Figs. I6-I9) or without (Figs. 20-28) a proximal shift in the posterior spur. In each case, the band is expanded and the tibia is modified in similar ways, (compare Figs. I4, I5, with 26, 27). Jeannel ( I94I) proposed the terms Isochaeta and Anisochaeta for two taxa based on the position of the posterior protibial spur. 'This arrangement was followed by Bell ( 1967) but not by Ball ( 1963) or Lindroth ( I969). Basing conclusions on the relationships of higher categories or simplistic data from part of a functional system is unsatisfactory on methodological grounds. Jeannel's arrangement is also faulty on practical grounds. The spur insertions of the mesotibia and of the least specialized protibiae are level or nearly so, i.e., the spurs are isochaetous. Yet, Jeannel considered some of these slightly differentiated forms to be anisochaetous, e.g., cicindelines, Opisthius.

Figs. 6-31. Posterior (even numbered Figs.), and medial views of carabid protibiae. Figs. 6, 7, Opisthius richardsoni; Figs. 8, 9, Carabus nemoralis; Figs. 10, 11, Hiletus versutus; Figs. 12, 13, Nomius pygmaeus; Figs. 14, 15, Pterostichus lucublandus; Figs. 16, 17, Helluomorphroides texana; Figs. 18, 19, Agra sp.; Figs. 20, 21, Trachypachus gibbsi; Figs. 22, 23, Metrius contractus, Figs. 24, 25, Mystropomus regularis; Figs. 26, 27, Tropopsis marginicollis; Figs. 28, 29, Gehringia olympica; Figs. 30, 31, Platycerozaena panamaensis.

Setal aggregations, indicated by dotted lines, limits of antennal channel shown with a dashed line. Scale limits beneath odd numbered figs. indicate width of antennal segment 9. Lettered brackets enclose protibiae of the same grade of development; see text for explanation. 
A different arrangement is obtained by considering divergence from an unspecialized tibia on the basis of posterior spur position relative to the tibial apex and to the most proximal point of the setal band. The protibia of Opisthius, for example, is little modified, yet cleaning setae are present; the antenna cleaners of other carabids can be derived from this sort of configuration along two parallel evolutionary pathways. In the isochaetous pathway, large proximal shift of the setal band occurs without shift of the posterior spur; while in the anisochaetous pathway, shift of band and spur occur together.

In each pathway, divergence from an unspecialized protibia has similar components:

I) Proximal development, elongation and differentiation of the setal band into a distal and a proximal cleaning portion.

2) Origin and development of the medial expansion and the cleaning arc.

3) Shift of the antennal channel from vertical to oblique.

4) Anterior-posterior compression of the tibia.

5) Degree of development of anterior and posterior setal rows.

Based on the degree of development in the above mentioned factors, the forms examined can be divided into three grades diagnosed as follows:

Grade A: Setal band short, almost entirely horizontal, located close to distal rim of medial face; confluent zone, if present, very short; $\mathrm{SB} / \mathrm{Tb}$ less than 20 per cent. Medial expansion absent. Antennal channel long, vertical. Anterior row always present, posterior row may not be used in cleaning. Tibia not compressed antero-posteriorly.

Grade B: Setal band long with distinct vertical section and confluent zone, $\mathrm{SB} / \mathrm{Tb}$ between $26-58$ per cent, but is usually less than 40 per cent. Confluent zone short, ranging from I5-35 per cent of the length of the band. Medial expansion present, except in Hiletus, but is usually not shifted far anteriorly. Antennal channel shallow and developed far above clip setae, or not. Tibia not compressed antero-posteriorly.

Grade $C$ : Setal band, long (SB/Tb 33-69 per cent) divided into a large distal region, or confluent zone, and a proximal cleaning arc. Distal region varying from 33-69 per cent the length of the setal band. Medial expansion well developed anteriorly. Channel deep, short, does not extend above clip setae. Anterior and posterior rows, if present, usually do not form cleaning aggregations. 
Grade A: Cicindelini, 'Carabini* (in part), Cychrini*, Opisthiini*, Enceladini

Grade B: Trachypachidini*, Omophronini, Notiophilini*, Elaphrini, Loricerini, Promecognathini**, Siagonini***, Migadopini, Hiletini*, Nomiini, Psydrini, Merizodini**, Bembidiini, Pogonini, Carabini (only Pamborus*), Ozaenini (only Metrius*** and Mystropomus***)

Grade C: Members of 40 other tribes.

*denotes groups with open procoxal cavities, and ** forms with advanced grade $B$ configurations.

Table I. Distribution of grade A and B antenna cleaners within the Carabidae.

The distribution of antenna cleaner grades within the Carabidae, is given in Table I. Each grade is characterized more fully below.

The setal band in grade $\mathrm{A}$ is almost entirely horizontal and situated very close to the distal rim of the tibia. In some forms (Opisthius, Figs. 6, 7; Cicindela) there is almost no confluent region between the anterior row and a vertical section of the band, while in others (Carabus, Figs. 8, 9, Nebria) there is very small confluent zone.

The gross shape of the tibia is only slightly modified for antenna cleaning. The proximal region is slender; distally it is broadened (Figs. 2, 8). The medial face bears a slight concavity or antennal channel that extends up the length of the tibia far above the setal band. In some grade A forms, e.g., Carabus (Figs. 2, 9), the anterior row is dense distally and is a cleaning element while the posterior row consists of a few widely spaced setae and is not a part of the cleaning system. In others, e.g., Enceladus, Cicindela, Scaphinotus, and Opisthius (Figs. 6, 7), both the anterior and posterior rows are modified distally into triangular cleaning tufts, many setae wide, that may obscure portions of the setal band. Proximally, the setae of each row are widely spaced and in a single file.

Grade B configurations are variable. Hiletus (Figs. IO, II) and Mystropomus (Figs. 24, 25) represent the least and most modified extremes respectively. It is likely that if more forms were examined, the gap between grades $\mathrm{B}$ and $\mathrm{C}$ would be quite small.

The setal band ranges from $26-58$ per cent of the length of the tibia and is divisible into a straight distal, confluent region and a proximal sinuous portion that cleans the antenna. The vertical con- 
fluent zone is short, frequently less than 20 per cent the length of the band. This section is the largest in Mystropomus, Metrius and Promecognathus where it is 30, 34, and 35 per cent respectively. The proximal section begins by curving posteriorly and goes horizontally across the tibial face and then curves dorsally and extends vertically up the tibia. Except in Hiletus (Figs. IO, I I), the vertical proximal section of the band is found on part of a flattened, medially expanded section of the tibia. The medial expansion is shaped like a triangle whose apex is at the level of the clip or guide setae and/or the most proximal point of the setal band, (Figs. I, $22 \mathrm{MEx}$ ). The distal side of this triangle is curved in a gentle arc and bears band setae; while the proximal side, which is less flattened, forms the posterior border of the antennal channel. The medial expansion varies greatly in development and orientation. In some forms (Nomius, Figs. I2, 13) it is almost entirely vertical with only a slight anterior shift. The channel is parallel to the tibial long axis, as in Carabus (Fig. 2). In others (Mystropomus, Metrius, Figs. 22-25, and Promecognathus) the expanded region and the band are shifted distinctly anteriorly, but the channel extends far above the clip setae. As the tibia is expanded antero-medially, the clip setae and the proximal part of the band come closer to the level of the confluent zone. The anterior setal row consists of tightly packed short setae in single file and is probably used in antennal grooming (Figs. I, I I, I3, 23, 25). The posterior row is formed from large, widely spaced setae (Fig. 2r) or is absent (Fig. 23).

In Grade C, the setal band is divided into a very long, straight, vertical distal region and a curvaceous proximal cleaning section. The anterior row is absent in many of these forms, in which case the non-grooming section of the band is called the distal zone (Fig. $3 \mathrm{D})$. The size of the distal section of the band readily characterizes most grade $\mathrm{C}$ configurations; it ranges from 33 to 69 per cent of the band length ( 15 to 34 per cent in grade B forms). This large distal increase in a non-cleaning part of the band results, of course, in a proximal shift of the cleaning elements (Figs. I4, I6, 26).

The proximal antenna cleaning part of the band occurs on a vertical, highly curved region of the tibia. This cleaning arc, in posterior view, is distinct (Fig. $26 \mathrm{~A}_{\mathrm{c}}$ ). The cleaning arc has been formed by a complex set of modifications in tibial molding. The flattened medial expansion is larger than that of grade B configurations. The tibia along the distal region of the band is also produced medially. Antero-posterior compression of the entire tibia brings the ends of the cleaning arc closer together so that they lie in nearly 
the same vertical plane. (Compare medial and posterior views of Nomius, Figs. I2, I3, with those of Helluomorphroides, Figs. I6, I7). The deep antennal channel begins at, and has the same curvature as, the cleaning arc. It then extends obliquely across the medial face and ends slightly above the clip setae (Fig. $3 \mathrm{Ch}$ ).

The anterior row is absent in grade $\mathrm{C}$ anisochaetous forms, but may be present and be a cleaning element in some ozaenines, e.g., Tropopsis (Fig. 27). In a few genera of the lebiine complex the posterior spur is lost, e.g., Agra (Figs. I8, I9); Taicona, Lebia ( $\mathrm{Habu}$, I967, Figs. I7, I 8). The tibia, in a few genera, has become very setose distally, e.g., Tropopsis (Fig. 27); and in some of these, the setae are so densely packed that the distal zone of the band is not recognizable, e.g., Agra, Platycerozaena (Figs. I9, 3i ). In many anisochaetous forms, a short linear cluster of relatively fine setae originates close to and above the insertions of the anterior spur and extends posteriorly for a short distance, e.g., Helluomorphroides, Pterostichus (Figs. 3, I5, I7 DC); ( $\mathrm{Habu}$ I967, Figs. 5-29). These distal cluster setae are modified ring setae and may play a role in grooming the mesotibia.

Behavior. Antennae cleaning and other aspects of grooming behavior of two carabid species were studied in detail and photographed. The grade A antenna cleaner of one species, Scaphinotus (Brennus) stratiopunctatus (Chaudoir) (Cychrini), is similar to

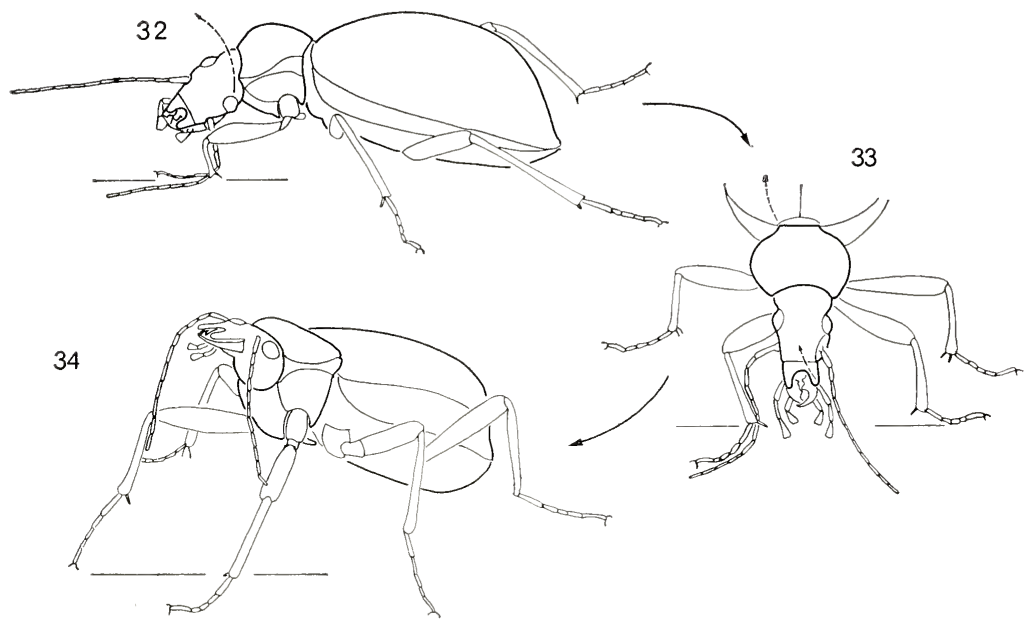

Figs. 32-34. Antenna cleaning behavior of Scaphinotus (Brennus) stratiopunctatus (Chaudoir). See text for details. 
that of Carabus (Figs. 2, 8, 9); while the grade $\mathrm{C}$ configuration of the other species, Pristonychus complanatus Dejean (Agonini), is similar to that of Pterostichus (Figs. 3, 14, 15).

Placing a drop of clove oil on an antenna stimulates rapid grooming behavior, even under the high light intensities used for motion picture photography. Except for rate, antenna cleaning behavior of beetles stimulated with clove oil differs little from that observed in carabids subjected to less violent stimuli (talc, india ink) at low light levels.

Scaphinotus begins an act of antenna grooming by lowering the body and by lowering the head and twisting it ventrally towards the side about to be cleaned. The antenna is held nearly perpendicular to the body. The proleg is then raised and lowered on the antenna near segment one. The antenna is now located between the tibial spurs and held against the setal band by the clip setae. The proleg is depressed until it touches the substrate, moving segments one to four or five through the cleaning setae (Fig. 32). The rest of the antenna is drawn through the antenna cleaner by raising the head and the rest of the body (Figs. 33, 34). The proleg is stationary after reaching the substrate.

As the antenna is being cleaned, it is bent into three sections (Fig. 33). The segments about to be cleaned lie on or close to the substrate, next to the tarsi, and are nearly perpendicular to the
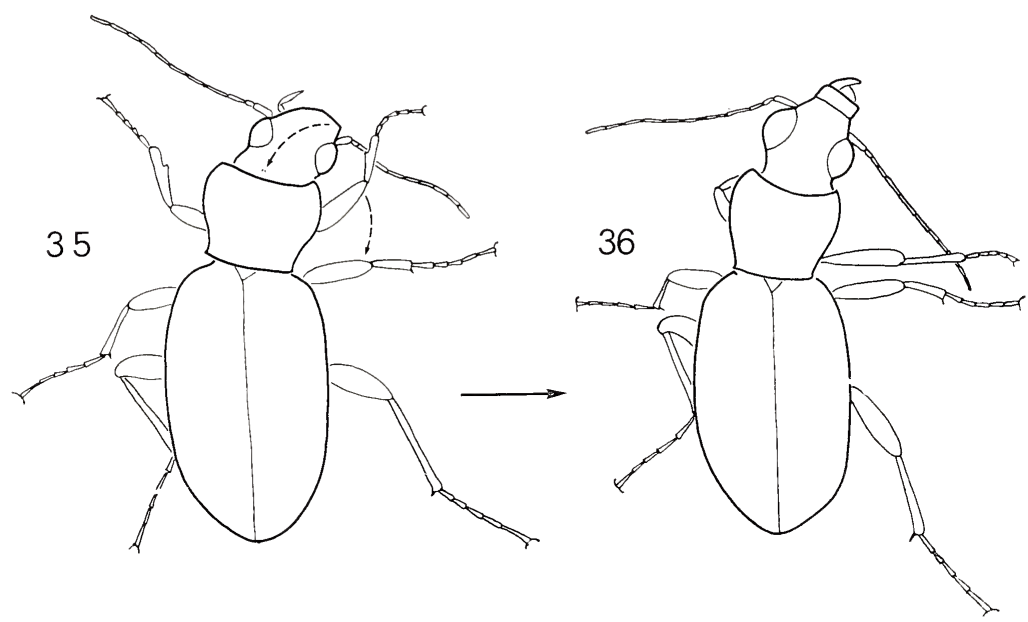

Figs. 35, 36. Antenna cleaning behavior of Pristonychus complanatus De. jean. See text for details. 
segments just cleaned which are in the channel above the setal band. From the channel, the proximal segments curve broadly to the antennal insertion. Only rarely are both antennae cleaned simultaneously.

In Pristonychus, the proleg is lowered on the extended antenna. The large clip setae engage the antenna and press it against the setal band (Fig. 35). The antenna is drawn through the cleaner by the proleg's posterior movement, which is generated by coxal rotation, as well as by dorsal movements of the head and thorax (Fig. 36). During cleaning, the antenna is not bent and the apical segments do not touch the substrate.

In both species, the protibial antenna cleaner is rubbed against the mesotibia after grooming the antenna several times. Occasionally the protibia is drawn through the mouth parts. The meso- and metatibia bear grooming setae. Fragmentary data indicate that a grooming system involving, in part, anterior movement of particulate matter to the protibia where it is ingested may be present in carabids. Such a system is known in ants (Sudd 1967).

Only about half the surface area, but most of the sensory regions, of a flattened antennal segment can come in contact with the band setae during a single act of grooming (Fig. $5 \mathrm{SE}$ ). Rotation of the antenna through movement of segment one could permit the other half to be cleaned.

Discussion. The effect of grooming on cuticular surfaces in carabids and other insects is poorly known. Particulate matter is, of course, quickly removed. The metapleural gland in ants secretes a material with antibiotic properties that is spread over the body surface by grooming (Maschwitz, et al, 1970). The association of single cell glands with antenna cleaning setae and other grooming bristles in carabids and other forms suggests that more than mechanical removal of detritus is involved in grooming. In any case, until these grooming functions become known, it would be useless to speculate on the specific selection pressures that have led to the development and differentiation of the carabid antenna cleaner. The arguments for biological improvement to be developed below are based on differences in mechanics, not on differences of ultimate function. The conclusions drawn from such observations are first approximations.

The grade $\mathrm{C}$ antenna cleaning mechanism is an improvement over the grade $\mathrm{A}$ type. For effective cleaning, the width of the antennal segment being groomed should be parallel to, and lie snugly against, the setal band, as in Fig. 5. If otherwise, only part of the surface 
of a segment will be groomed, or uneven pressure will be applied. In grade A systems, the setal band is horizontal and located close to the tibial apex. These facts impose restrictions on grooming behavior. The setal band and the flattened surfaces of the apical segments can be parallel only if the tibia is placed in a narrow zone near the level of the antennal insertion. Outside this zone, dorsal movement of the head or posterior rotation of the coxa will draw the antenna obliquely through the band. This is especially so since the antennal segments (looked at as an ellipse in cross section) are capable of little motion parallel to the semi-major axis. The protibia of Scaphinotus, and perhaps other grade A forms as well, is stationary after reaching the substrate, maintaining the geometric relationship between the antennal surface and the band throughout a sequence.

Since the band is located close to the tibial apex, and since the spurs contact the substrate during grooming, the antennal segments about to be cleaned are dragged across the substrate (Fig. 33). And, the antenna, as a whole, undergoes considerable bending, parallel to the semi-minor axis.

In grade $\mathrm{C}$ configurations, the cleaning arc is vertical and located above the tibial apex. Movement of the tibia will not pull the antenna out of alignment with the band since the antenna is gripped by the clip setae and is capable of considerable movement parallel to the semi-minor axis. While the antenna is drawn through the cleaning setae, by movements of both the head and proleg, the apical segments do not contact the substrate nor is the antenna bent (Figs. 35, 36).

In permitting use of an additional grooming movement, coxal rotation, by developing vertical cleaning elements; and in preventing the antenna from contacting the substrate, by moving the cleaning seatae proximally, the grade $\mathrm{C}$ system is an improvement over grade A. The setal band in grade $\mathrm{B}$ forms has a vertical grooming component that is not developed far above the tibial apex (Fig. 13). In these forms, coxal rotation can be a grooming movement but the antenna may come in contact with the substrate. Grade B systems may be intermediate functionally as well as structurally. And so, the three grades of antenna cleaners, defined above on structural criteria, represent grades of improvement in the antenna cleaning mechanism.

There are two types of evidence which suggests that the three grades represent sequences of historical development: 
I) the nature of putative reductions of the antenna cleaner mechanism, and

2) correlation of presence of either grade $A$ or $B$ cleaners with that of another presumably primitive character - the open procoxal cavity.

Reduction of the antenna cleaner is found in very few groups. In several ozaenine genera, e.g., Platycerozaena (Figs. 30, 3I), Physea, Ozaena (Banninger 1927, Figs. I, 2, 7) the curvature of the cleaning arc is reduced and the antennal sensory regions are very much smaller than those of related genera, e.g., Tropopsis (Figs. $26,27)$.

A very long, straight setal band is present in primitive paussids, e.g., Protopaussus, Carabidomemnus, Eohomopterus and some species of Arthropterus. In these forms, the antennae are not greatly modified and bear a moderate number of setae. The setal band is absent in other paussines, where the antennal segments may be greatly dilated and fused together (Darlington 1950: 60-65, Figs. 45-IO3, I $20-127$ ).

The antennae of Adelotopus (Pseudomorphinae) are not as long as the head and bear very few setae and sensillae. The antenna cleaner is greatly reduced, and may no longer be used in grooming. It consists of a few widely spaced setae arranged in a vertical row between the spurs. A single large straight seta near the posterior spur is probably a vestigial clip seta. In related genera, e.g., Sphallomorpha, the antenna is long, bears dense setation, and the cleaner is a normal grade $\mathrm{C}$ type.

In each case, both the antenna and the cleaner have undergone reduction. Furthermore, the grade $\mathrm{C}$ cleaners are simply reduced; there is no evidence of reversal towards a grade $\mathrm{B}$ configuration. The setose regions of forms with either grade $\mathrm{A}$ or $\mathrm{B}$ cleaners are quite variable in size, but except for the trachypachidines, they are much larger than in the forms cited above as examples of reduction.

Except for Gehringia, carabids with open procoxal cavities have either a grade $\mathrm{A}$ or $\mathrm{B}$ antenna cleaner, while forms with closed coxal cavities have either a grade B or C cleaner, except for the cicindelines and Enceladus (Table I). Closed coxal cavities and related structures represent a mechanical improvement in the promesothoracic joint. Open cavities are probably primitive in carabids, (Hlavac, unpublished observations). Improvement of the antenna cleaner is then correlated with improvement of the pro-mesothoracic joint.

Reduction of the antenna cleaner mechanism is a rare phenomenon. 
The least specialized cleaners are found in forms with the least specialized and possibly primitive pro-mesothoracic joint. The grades of antenna cleaners probably represent sequences of historical development, and the terms primitive, intermediate, and advanced can be applied to $\mathrm{A}, \mathrm{B}$, and $\mathrm{C}$ grade configurations, respectively.

It has been argued above that two developmental pathways have been employed in the parallel differentiation of the carabid antenna cleaner, and that the grades may represent historical sequences of mechanical improvement. The major cleaning element, the setal band, is a modified portion of the horizontal ring of setae about the tibial apex. Mechanical improvement of a primitive, i.e., grade A, configuration consists of a shift of the setal band from horizontal to vertical so that coxal rotation can be used in antenna grooming. The pathways are geometric alternatives; the setal band is shifted proximally and vertically with or without the posterior spur. Improvement then implies choice of pathway. Polyphyletic adoption of a given pathway is readily visualized. Similarity of pathway is consistent with, but is not in itself, evidence for phylogenetic relationship. Each case must be dealt with separately and evidence collected from other functional systems before conclusions are reached. When such evidence becomes available, the distributions of the several types of antenna cleaner will be germaine to a discussion of carabid evolution.

\section{Summary}

I. An antenna cleaner, formed from setal aggregations, is present on the protibia of nearly all carabid beetles.

2. The major cleaning element, the setal band, consists of tightly packed bristles arranged in single file. The setal band is serially homologous with a section of the apical ring of setae between the tibial spurs on the meso- and metalegs.

3. In the least specialized, and probably primitive antenna cleaners, the setal band is apical, horizontal and located between the nearly level spur insertions. In others, the band is lengthened, developed proximally and may be divided into cleaning and noncleaning sections.

4. Based on the degree of divergence of the setal band and related structures, the forms examined can be divided into three grades.

5. The most specialized configuration is found in the majority of carabid tribes; the least modified antenna cleaner is present in only a few tribes. 
6. Specialized antenna cleaners may have evolved in parallel along two pathways: the setal band is shifted with or without the posterior spur.

7. In permitting use of coxal rotation as a grooming movement and in preventing the antenna from being dragged across the substrate, antenna grooming behavior of a form with a highly specialized cleaner represents a mechanical improvement over a form with a slightly modified configuration.

8. Reduction of the antenna cleaner is uncommon and always occurs with reduction in antennal setation.

9. The least specialized antenna cleaners are found in forms with the least specialized pro-mesathoracic joint.

ro. The grades of antenna cleaners may represent historical sequences of mechanical improvement.

ASp - anterior spur

Abrreviations Used in the Figures

ASR - anterior setal row

$\mathrm{Ch}$ - antennal channel

CLS - clip seta (ae)

$\mathrm{CON}$ - confluent region of $\mathrm{SB}$ and $\mathrm{ASR}$

$\mathrm{D}-$ distal region of $\mathrm{SB}$ (三 confluent region when $\mathrm{ASR}$ is present)

DC - distal cluster

PSp - posterior spur

PSR - posterior setal row

$R$ - row (s) of setae on mesotibia

Rng - apical ring of setae on mesotibia

$\mathrm{SB}$ - setal band

$\mathrm{SE}-$ setose regions of the antenna

BALL, G. E.

\section{References Cited}

1963. Carabidae. In R. H. Arnett, Jr., The Beetles of the United States, pp. 55-181.

BANNINGER, M.

1927. Die Ozaenini. Deutsche Ent. Zeit. (1927), pp. 177-216.

BELL, R. T.

1964. Does Gehringia belong to the Isochaeta? Coleop. Bull. 18: 59-61.

1967. Coxal cavities and the classification of the Adephaga. Ann. Ent. Soc. Amer. 60: 101-107.

Darlington, P. J., Jr.

1950. Paussid beetles. Trans. Amer. Ent. Soc. 76: 47-142. Habu, A.

1967. Carabidae. Truncatipennes group. Fauna Japonica, Tokyo, 1-338. JANDER, U.

1966. Untersuchungen zur Stammegeschichte von putzbewegungen von Tracheaten. Z. Tierpsychol. 23: 799-844.

JEANNEL, R.

1944. Coléoptères Carabiques. Faune de France 39: 1-571. 
LINDROTH, C. H.

1969. The ground-beetles of Canada and Alaska, Part 1. Opus. Ent. Suppl. 35 : I-XLVIII.

Maschwitz, V., K. KoOb, and H. SchildKnecht.

1970. Ein beitrag zur funktion der metathoracalarüse der Ameisen. J. Insect Physiol. 16: 387-404.

SudD, J. H.

1967. An introduction to the behavior of ants. St. Martins Press, N.Y. 1-200. 


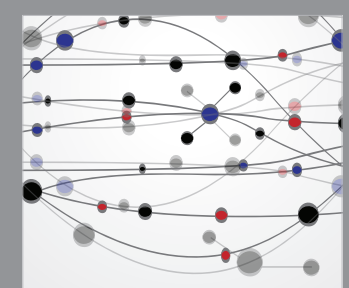

The Scientific World Journal
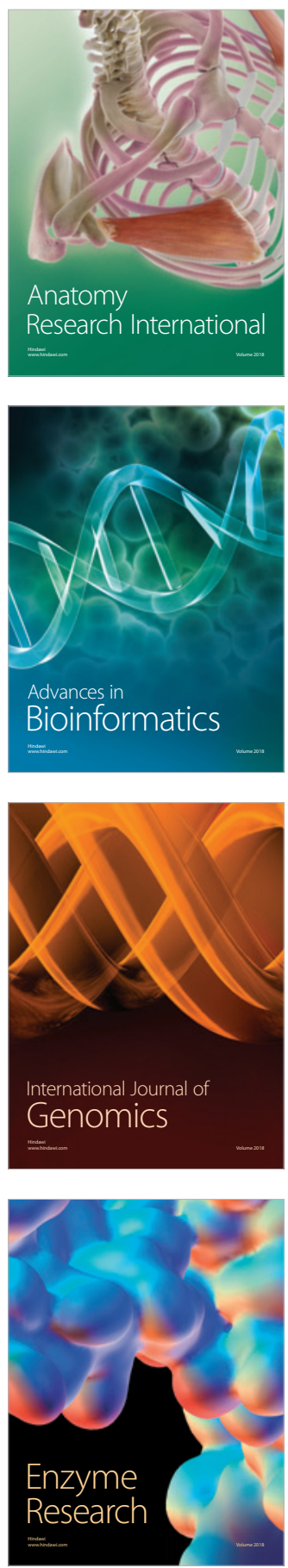
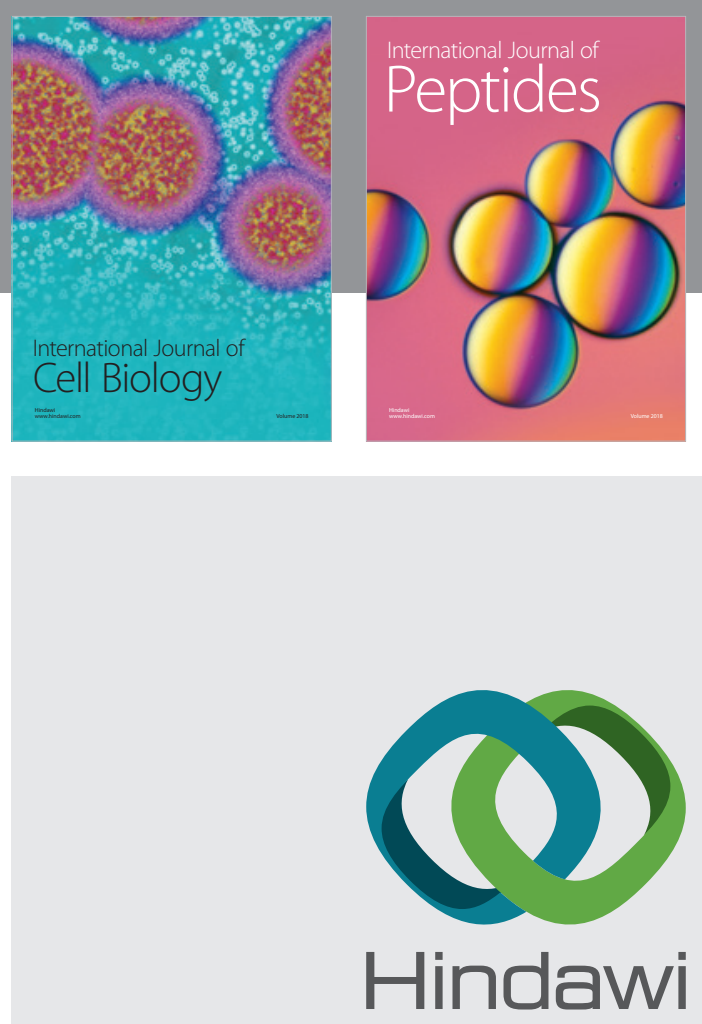

Submit your manuscripts at

www.hindawi.com
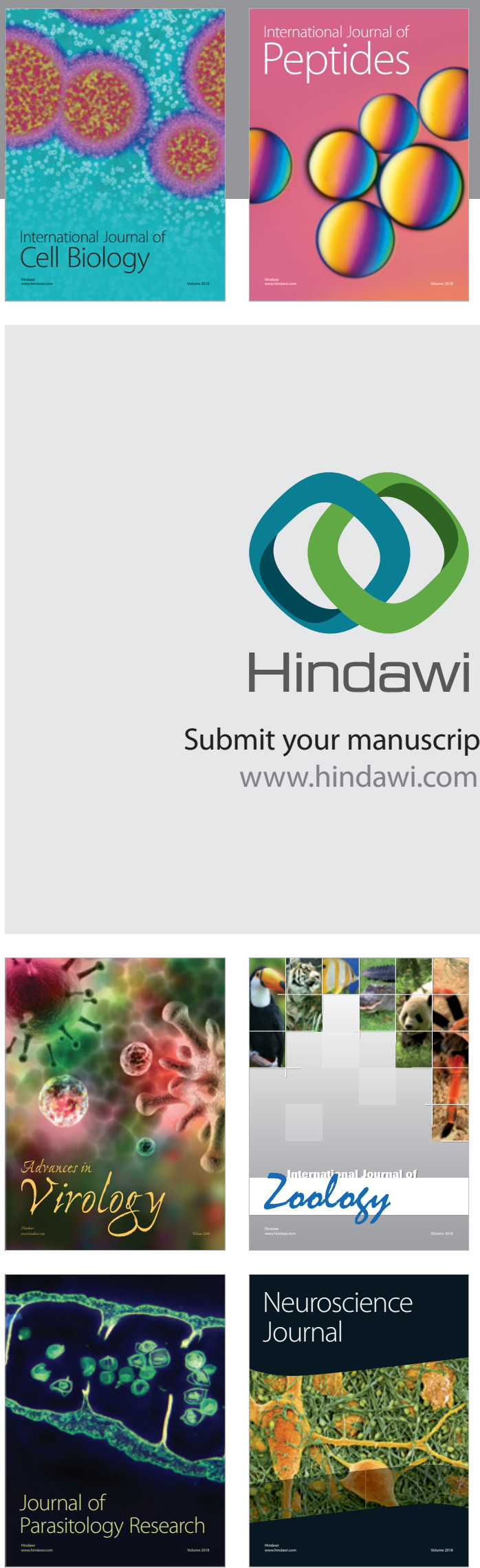
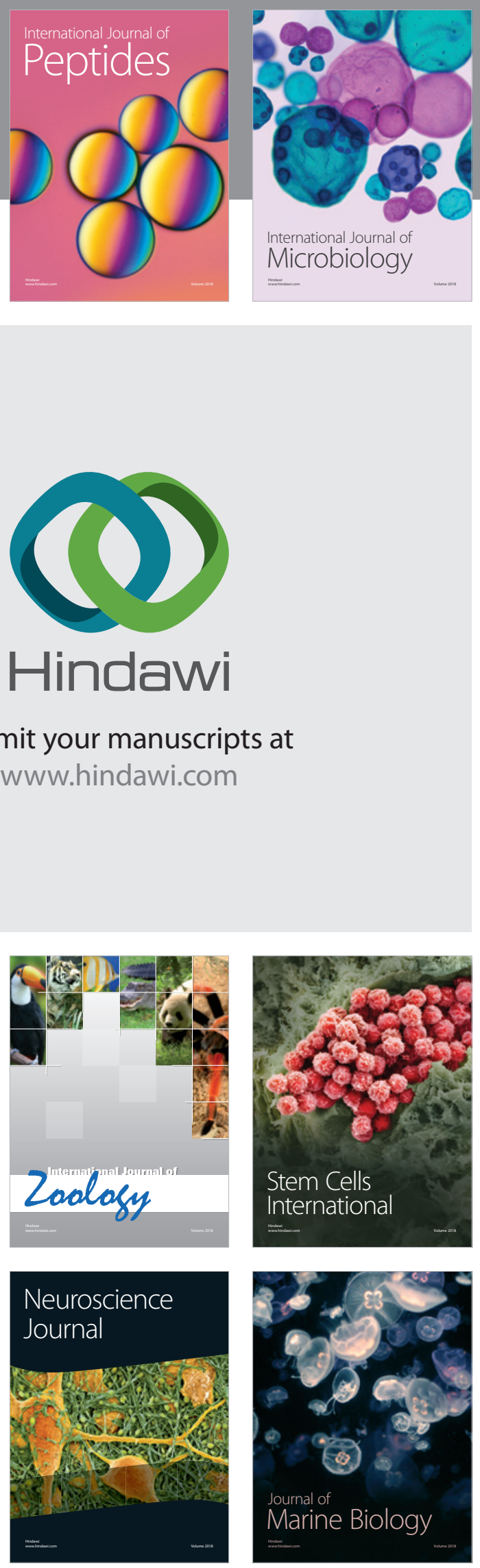
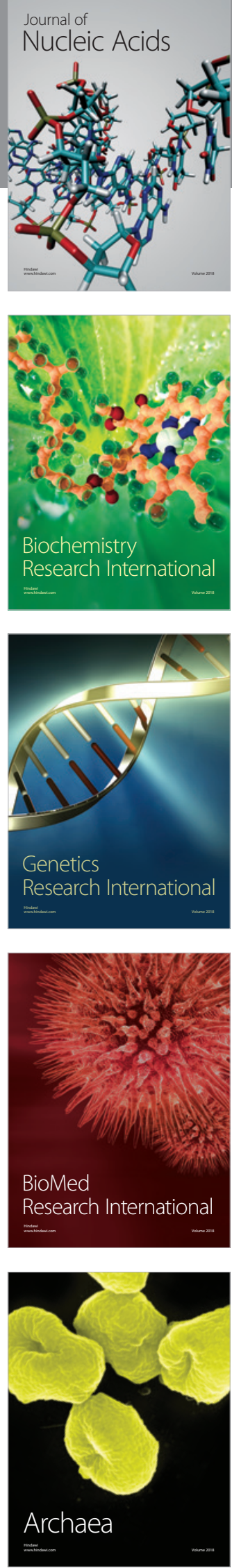